NASA/TM-2005-213985

\title{
Performance and Mass Modeling Subtleties in Closed-Brayton-Cycle Space Power Systems
}

Michael J. Barrett

Glenn Research Center, Cleveland, Ohio

Paul K. Johnson

Analex Corporation, Brook Park, Ohio 
Since its founding, NASA has been dedicated to the advancement of aeronautics and space science. The NASA Scientific and Technical Information (STI) Program Office plays a key part in helping NASA maintain this important role.

The NASA STI Program Office is operated by Langley Research Center, the Lead Center for NASA's scientific and technical information. The NASA STI Program Office provides access to the NASA STI Database, the largest collection of aeronautical and space science STI in the world. The Program Office is also NASA's institutional mechanism for disseminating the results of its research and development activities. These results are published by NASA in the NASA STI Report Series, which includes the following report types:

- $\quad$ TECHNICAL PUBLICATION. Reports of completed research or a major significant phase of research that present the results of NASA programs and include extensive data or theoretical analysis. Includes compilations of significant scientific and technical data and information deemed to be of continuing reference value. NASA's counterpart of peerreviewed formal professional papers but has less stringent limitations on manuscript length and extent of graphic presentations.

- TECHNICAL MEMORANDUM. Scientific and technical findings that are preliminary or of specialized interest, e.g., quick release reports, working papers, and bibliographies that contain minimal annotation. Does not contain extensive analysis.

- CONTRACTOR REPORT. Scientific and technical findings by NASA-sponsored contractors and grantees.
- CONFERENCE PUBLICATION. Collected papers from scientific and technical conferences, symposia, seminars, or other meetings sponsored or cosponsored by NASA.

- SPECIAL PUBLICATION. Scientific, technical, or historical information from NASA programs, projects, and missions, often concerned with subjects having substantial public interest.

- TECHNICAL TRANSLATION. Englishlanguage translations of foreign scientific and technical material pertinent to NASA's mission.

Specialized services that complement the STI Program Office's diverse offerings include creating custom thesauri, building customized databases, organizing and publishing research results ... even providing videos.

For more information about the NASA STI Program Office, see the following:

- Access the NASA STI Program Home Page at http://www.sti.nasa.gov

- E-mail your question via the Internet to help@sti.nasa.gov

- Fax your question to the NASA Access Help Desk at 301-621-0134

- Telephone the NASA Access Help Desk at 301-621-0390

- Write to:

NASA Access Help Desk

NASA Center for AeroSpace Information 7121 Standard Drive

Hanover, MD 21076 
NASA/TM-2005-213985

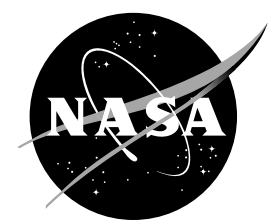

\section{Performance and Mass Modeling Subtleties in Closed-Brayton-Cycle Space Power Systems}

Michael J. Barrett

Glenn Research Center, Cleveland, Ohio

Paul K. Johnson

Analex Corporation, Brook Park, Ohio

Prepared for the

Third International Energy Conversion Engineering Conference

sponsored by the American Institute of Aeronautics and Astronautics

San Francisco, California, August 15-18, 2005

National Aeronautics and

Space Administration

Glenn Research Center 


\section{Acknowledgments}

NASA's Prometheus Nuclear Systems Program supported the work described within this paper, in whole or part, as part of the program's technology development and evaluation activities.

This report contains preliminary

findings, subject to revision as analysis proceeds.

Available from

NASA Center for Aerospace Information 7121 Standard Drive

Hanover, MD 21076
National Technical Information Service 5285 Port Royal Road Springfield, VA 22100 


\title{
Performance and Mass Modeling Subtleties in Closed-Brayton-Cycle Space Power Systems
}

\author{
Michael J. Barrett \\ National Aeronautics and Space Administration \\ Glenn Research Center \\ Cleveland, Ohio 44135 \\ Paul K. Johnson \\ Analex Corporation \\ Brook Park, Ohio 44142
}

\begin{abstract}
A number of potential NASA missions could benefit from closed-Brayton-cycle (CBC) power conversion systems. The human and robotic mission power applications include spacecraft, surface base, and rover scenarios. Modeling of CBC subsystems allows system engineers, mission planners and project managers to make informed decisions regarding power conversion system characteristics and capabilities. To promote thorough modeling efforts, a critical review of $\mathrm{CBC}$ modeling techniques is presented. Analysis of critical modeling elements, component influences and cycle sensitivities is conducted. The analysis leads to quantitative results addressing projections on converter efficiency and overall power conversion system mass. Even moderate modeling errors are shown to easily over-predict converter efficiencies by 30 percent and underestimate mass estimates by 20 percent. Both static and dynamic modeling regimes are evaluated. Key considerations in determining model fidelity requirements are discussed. Conclusions and recommendations are presented that directly address ongoing modeling efforts in solar and nuclear space power systems.
\end{abstract}

\section{Nomenclature}

$\begin{array}{ll}A & =\text { heat transfer area } \\ c & =\text { specific heat of solid } \\ h_{c} & =\text { convective heat transfer coefficient } \\ T & =\text { temperature of solid } \\ T_{e} & =\text { Far-field fluid temperature } \\ t & =\text { time } \\ V & =\text { volume of solid } \\ \eta & =\text { efficiency } \\ \Theta & =\text { dimensionless temperature } \\ \rho & =\text { density of solid } \\ \tau & =\text { characteristic time scale }\end{array}$

\section{Introduction}

CLOSED-Brayton-cycle (CBC) power conversion is one method that can be used in space power systems. Brayton system conceptual designs for milliwatt to megawatt power converters have been developed (Baggenstoss and Ashe ${ }^{1}$, Harty, et al. ${ }^{2}$, Shaltens and Mason ${ }^{3}$, Hyder et al. ${ }^{4}$, Mason $^{5}$ ). When optimizing a CBC-based power conversion system (PCS), numerous features affect overall system performance; a partial list of influential factors includes turbomachinery efficiency, heat exchanger effectiveness, working-fluid composition and cycle temperatures and pressures. 


\section{Literature Review}

More than 270 works on Brayton-related space power system topics appear in the literature over the last 30 years. Six examples of steady-state analyses are Tilliette ${ }^{6}$, Owen ${ }^{7}$, Baggenstoss and Ashe ${ }^{1}$, Barrett and Reid ${ }^{8}$, Mason $^{5}$ and Johnson and Mason'.

Tilliette ${ }^{6}$ examined 25-kWe-class Brayton systems. Liquid metal cooled and direct gas cooled reactors were evaluated as heat sources; fast and thermal spectrums were included. Recuperated and non-recuperated Brayton systems were evaluated. Tilliette demonstrated that a $\mathrm{CBC}$ was adaptable for all 10 of the configurations examined. Owen $^{7}$ evaluated $10-\mathrm{kWe}$ - to $100-\mathrm{kWe}$-class $\mathrm{CBC}$ concepts using pumped loop, heat pipe and direct gas reactor cooling schemes. Thermoelectric conversion was also examined; comparative advantages of a CBC system were given. Baggenstoss and Ashe ${ }^{1}$ detailed key mission design requirements for $\mathrm{CBC}$ systems. They examined power outputs from 0.5 to $3,300 \mathrm{kWe}$. Heat sources considered included isotope, solar and reactor; liquid-metal-cooled and direct-gas-cooled reactors were examined. Barrett and Reid ${ }^{8}$ evaluated $\mathrm{CBC}$ performance as influenced by working fluid molar mass and cycle peak pressure. Their results indicated performance degradation due to increased mechanical losses at higher operating pressures. Mason $^{5}$ gave an extensive assessment of a $100-\mathrm{kWe}$ CBC design including system-level optimization results for variations in key design parameters. Johnson and Mason evaluated design-point $\mathrm{CBC}$ performance as number of converters, cycle peak pressure and shaft speed varied. Off-design operating modes that reduced reactor heat input were also assessed.

Compared to steady-state assessments, far fewer CBC transient analyses have been published. Four relevant recent evaluations are Traverso et al. ${ }^{10}$, Traverso ${ }^{11}$, Ulfsnes et al. ${ }^{12}$ and Wright ${ }^{13}$. Using a mass inventory control scheme, Traverso et al ${ }^{10}$ showed stable behavior of a $24-\mathrm{kW}$ solar-dynamic CBC converter with heat rejection radiators subjected to orbital sink temperature periodicity. In a description of a transient code validation case, Traverso ${ }^{11}$ also showed the importance of thermal energy storage in the turbine wheel of a commercial microturbine. Ulfsnes $^{12}$ studied the transient behavior of a semi-closed $\mathrm{O} 2 / \mathrm{CO} 2$ gas turbine. The study confirmed the highly integrated complexity of component interactions in a closed cycle system. With the exception of shaft speed calculations, transient variations in gas constant and specific heat ratio were found to have only minor effects on overall cycle performance. Wright ${ }^{13}$ modeled an integrated closed-Brayton-cycle and gas-cooled fission reactor power system. The model demonstrated stable behavior and showed that the system was capable of load following. Wright showed that temperature feed back mechanisms in reactor control caused what he labeled "counterintuitive" behavior; his model response to a step decrease in electrical load was an increase in reactor power output.

\section{Present Objectives}

Cast in the context of previous studies, the present work has three principal objectives: to demonstrate the system-level impacts of differing levels of refinement in modeling closed-Brayton-cycle power conversion systems, to recommend a minimum $\mathrm{CBC}$ modeling fidelity for conceptual design studies, and to identify issues related to mass estimation and transient modeling related to the conceptual design of $\mathrm{CBC}$ energy conversion systems for space applications.

\section{Fidelity Necessity}

System and subsystem models are tools used to aid in answering engineering design questions. The requisite fidelity of a model depends on what questions are being considered. Different constraints exist for the development, execution and validation of steady-state versus transient simulations. For conceptual design and sizing of CBC power systems, steady-state thermofluid design models are typically used to generate performance and mass estimates. If dynamic interactions with other subsystems are of interest, an integrated transient model is needed to conduct the investigation. In either case, there exists a minimum set of component and subsystem models that are needed to adequately characterize the system. If one oversimplifies the models, erroneous conclusions may be drawn from the analysis results. Elaboration on some key influential factors is warranted.

\section{A. Steady State}

Many engineers are familiar with the thermodynamics of the ideal Brayton cycle. ${ }^{*}$ The cycle is frequently introduced in the first thermodynamics course of an undergraduate mechanical or aerospace engineering curriculum.

\footnotetext{
* In actuality, by its definition the Brayton cycle must be an ideal set of thermodynamic state paths that result in a closed process. The "closed-Brayton-cycle" vernacular is used to distinguish a closed-loop converter from an openloop gas-turbine engine. The nomenclature "ideal" Brayton cycle clarifies that real (non-ideal) component performance is not considered. In practice, real performance is included in many "Brayton" analyses.
} 
At first introduction, an instructor may also cover realbehavior of compressors, turbines and heat exchangers. From an introductory course then, we might model a recuperated $\mathrm{CBC}$ as shown in Fig. 1. This configuration shows the basic elements of a $\mathrm{CBC}$, but it omits bearings, compressor bleed flow paths (used to cool bearings and the alternator rotor), heat exchanger details, and elements of other subsystems that directly influence $\mathrm{CBC}$ performance. Parameters needed to solve the simple cycle thermodynamics of the Fig. 1 representation include turbomachinery efficiencies, recuperator effectiveness and irreversible component flow losses (or "pressure drops"). These performance parameters must be carefully selected to preserve the realness of the model. Overestimation of performance

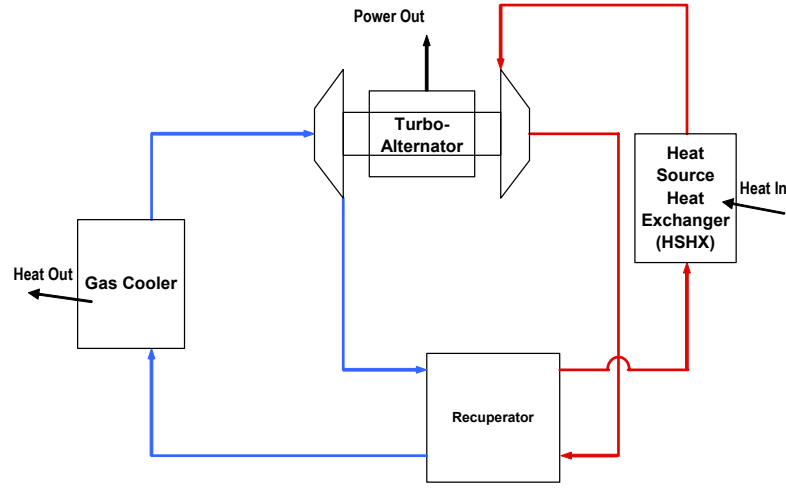

Figure 1. Simple recuperated Brayton cycle. capability can yield unrealistic cycle efficiencies; underestimation can forecast detrimentally heavy subsystem masses. As an illustration, we use a pedigreed high-fidelity CBC modeling code, the NASA Closed Cycle Engine Program (CCEP) $)^{8,9,14,15,16}$, to explore the effects of overestimating performance. Figure 2 shows a more realistic CBC diagram that includes heat rejection subsystem (HRS) information; inclusion of this subsystem is key to understanding gas cooler performance and auxiliary load requirements such as required pumping power. For convenience, the heat source subsystem is shown as a generic system because vastly different models are required for different heat sources such as solar, chemical, or nuclear. However, for the same reasons HRS definition is needed, some detailing of the heat source subsystem is also mandatory to complete a thorough power system analysis. Since we are not actually conducting a system analysis but instead are seeking to illustrate CBC modeling issues, the generic source subsystem will suffice for the present work. A $100-\mathrm{kWe}$, two-engine configuration is presented in Fig. 2; numerical values in the figure are multiplied or divided accordingly. Figure 2 represents the first oversimplified case in which we zero the compressor bleed flows, mechanical losses (bearings and windage) and electrical (EM) losses. Unrealistically optimistic turbomachinery efficiencies are also selected. The result is a configuration with each $50-\mathrm{kWe}$ engine running at $31.9 \%$ converter efficiency,

$$
\eta_{\text {converter }}=\text { alternator electrical output } / \text { cycle heat input }
$$

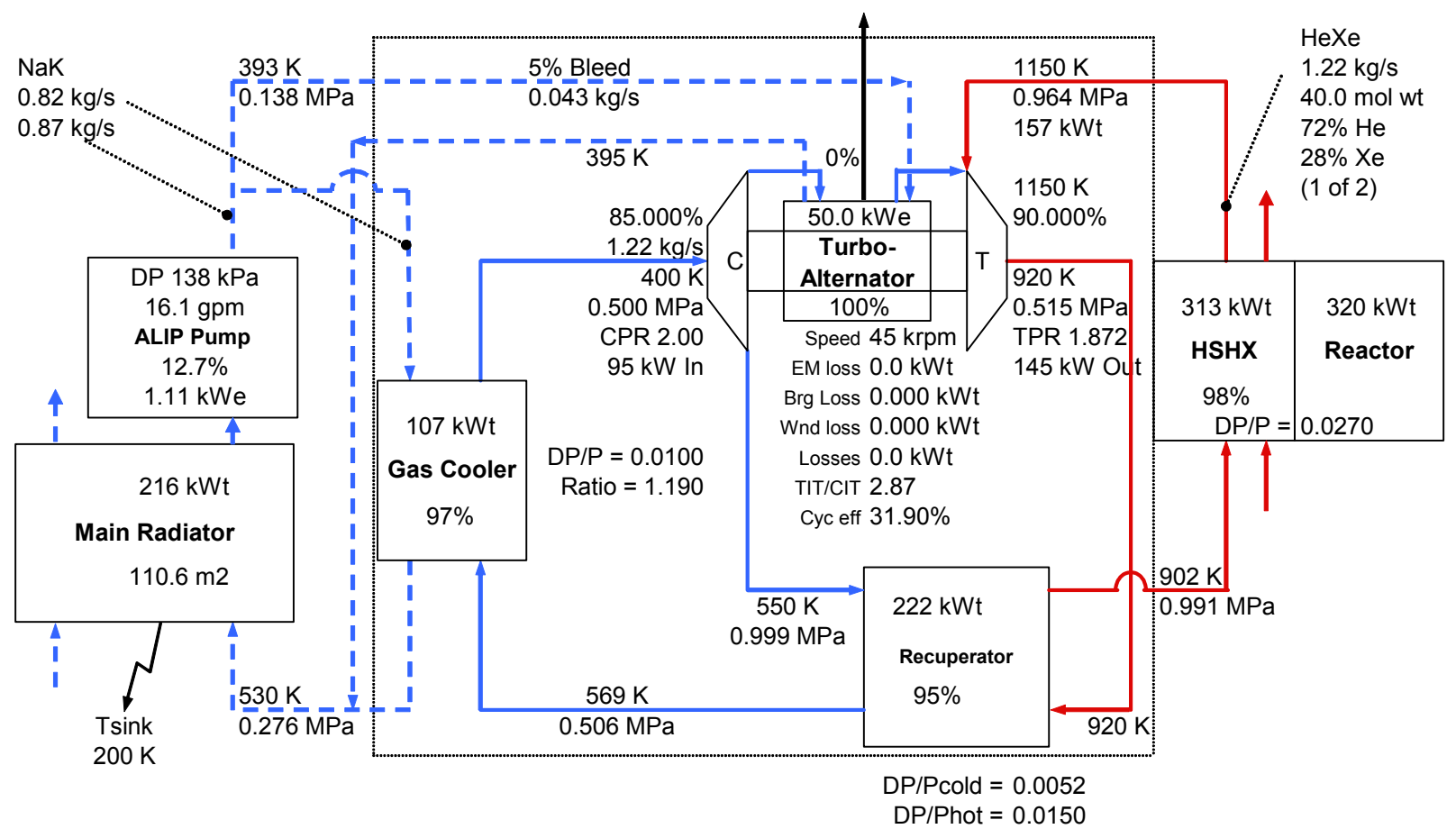

Figure 2. CBC with specified turbomachinery $\eta, 0 \%$ compressor bleed, no bearing, windage, or EM losses. 
In Fig. 3, we add 2\% compressor bleed flow for bearing and rotor cooling. At the entrance to the turbine, the mixing of compressor bleed flow with flow from the heat source heat exchanger (HSHX) leads to a lower turbine inlet temperature and degraded converter efficiency of $30.1 \%$. Figure 4 shows the effect of using design performance maps to estimate turbomachinery efficiencies. (Mean-line design codes are even better estimates of compressor and

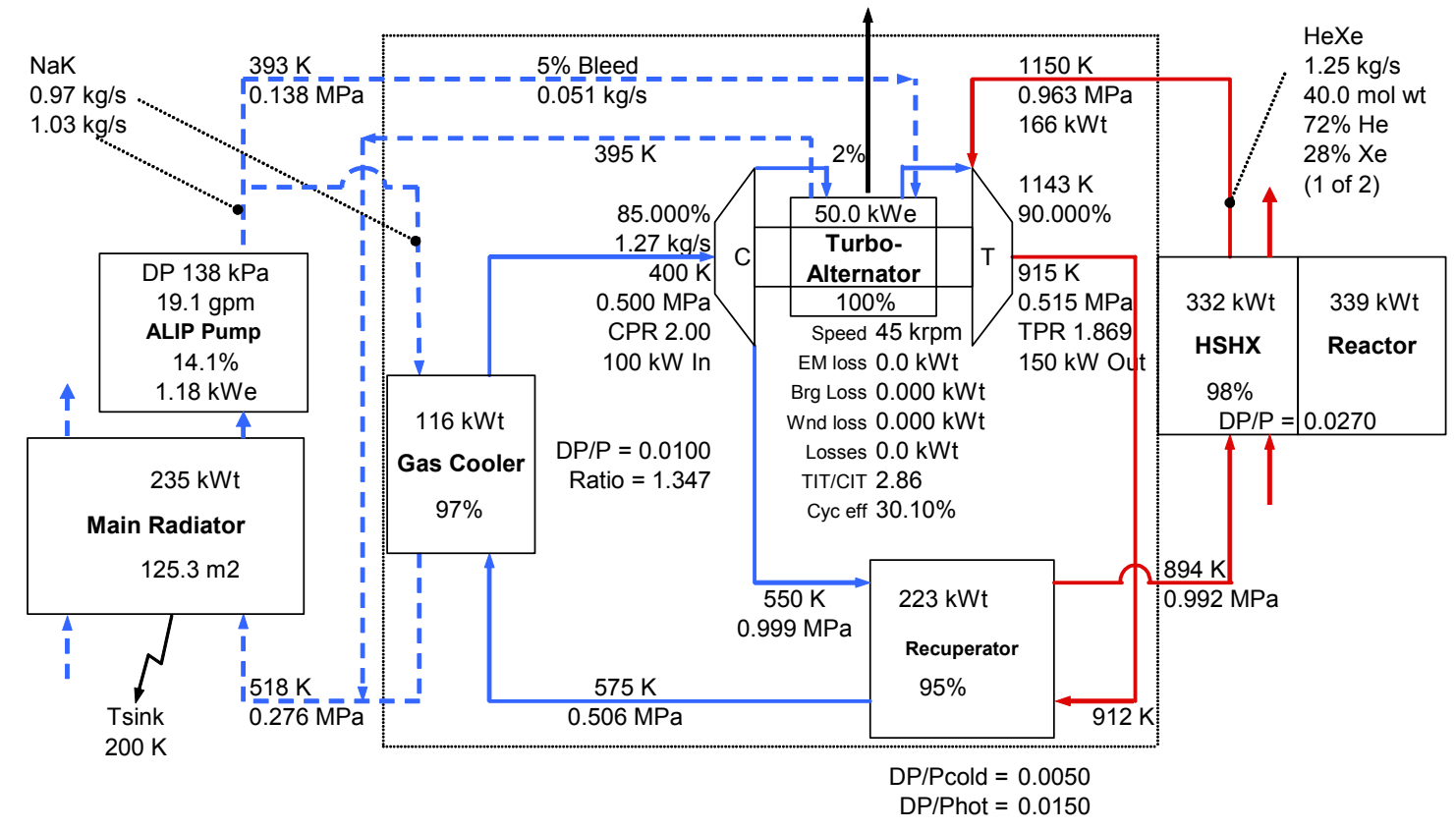

Figure 3. $\mathrm{CBC}$ with specified turbomachinery $\eta, 2 \%$ compressor bleed, no bearing, windage, or EM losses.

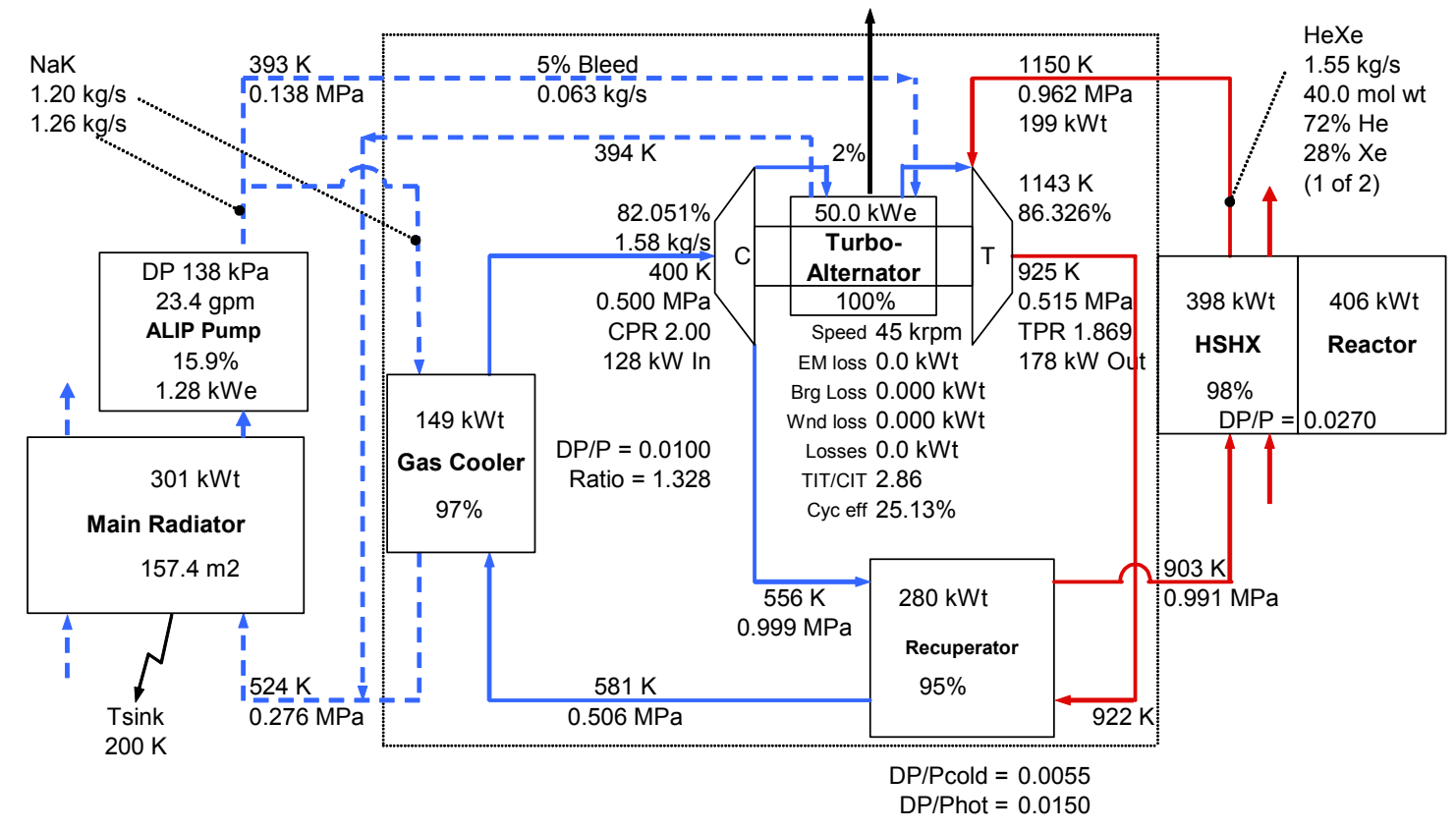

Figure 4. CBC with map-based turbomachinery $\eta, 2 \%$ compressor bleed, no bearing, windage, or EM losses. 
turbine performance and are preferred to generic conceptual design maps.) Even though the original polytropic efficiencies were held to less than $90 \%\left(e_{c}=87 \%, e_{t}=89 \%\right)$, the design performance maps for the corrected mass flow rates, specific speeds and pressure ratios represented reduce each wheel isentropic efficiency by three points or more ( $85 \%$ to $82 \%$ for the compressor; $90 \%$ to $86 \%$ for the turbine). The converter efficiency suffers and drops to $25.1 \%$. Figures 5 through 7 display cases that add bearing, windage and electromagnetic losses yielding progressively more realistic performance estimates. Ultimately, the Fig. 7 converter efficiency falls to $21.7 \%$. The fidelity increase from Fig. 2 to Fig. 7 revises the efficiency prediction from 31.9\% to 21.7\% - a relative reduction of

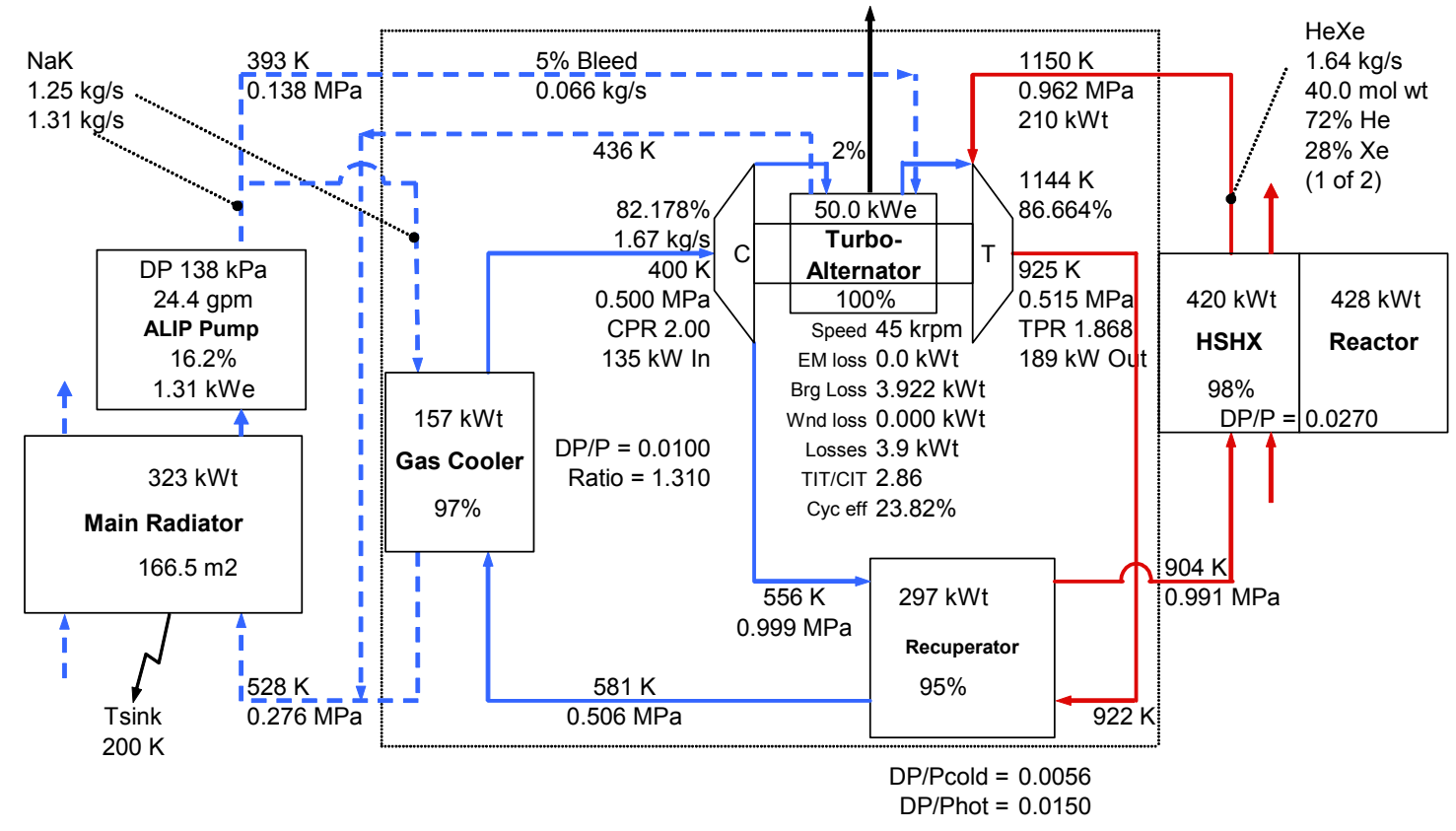

Figure 5. CBC with map-based turbomachinery $\eta, 2 \%$ compressor bleed, bearing losses only.

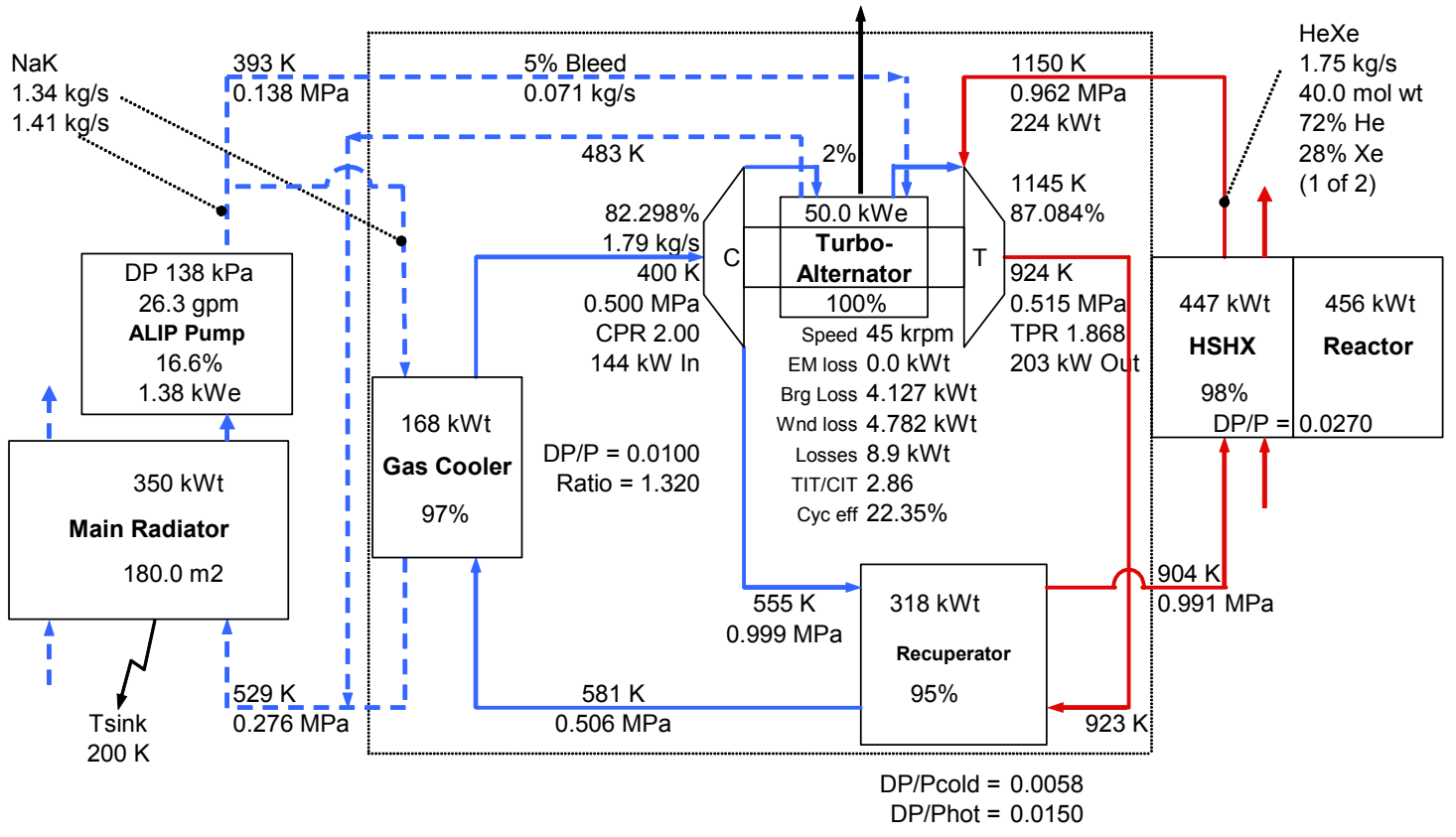

Figure 6. CBC with map-based turbomachinery $\eta, 2 \%$ compressor bleed, bearing and windage losses only. 


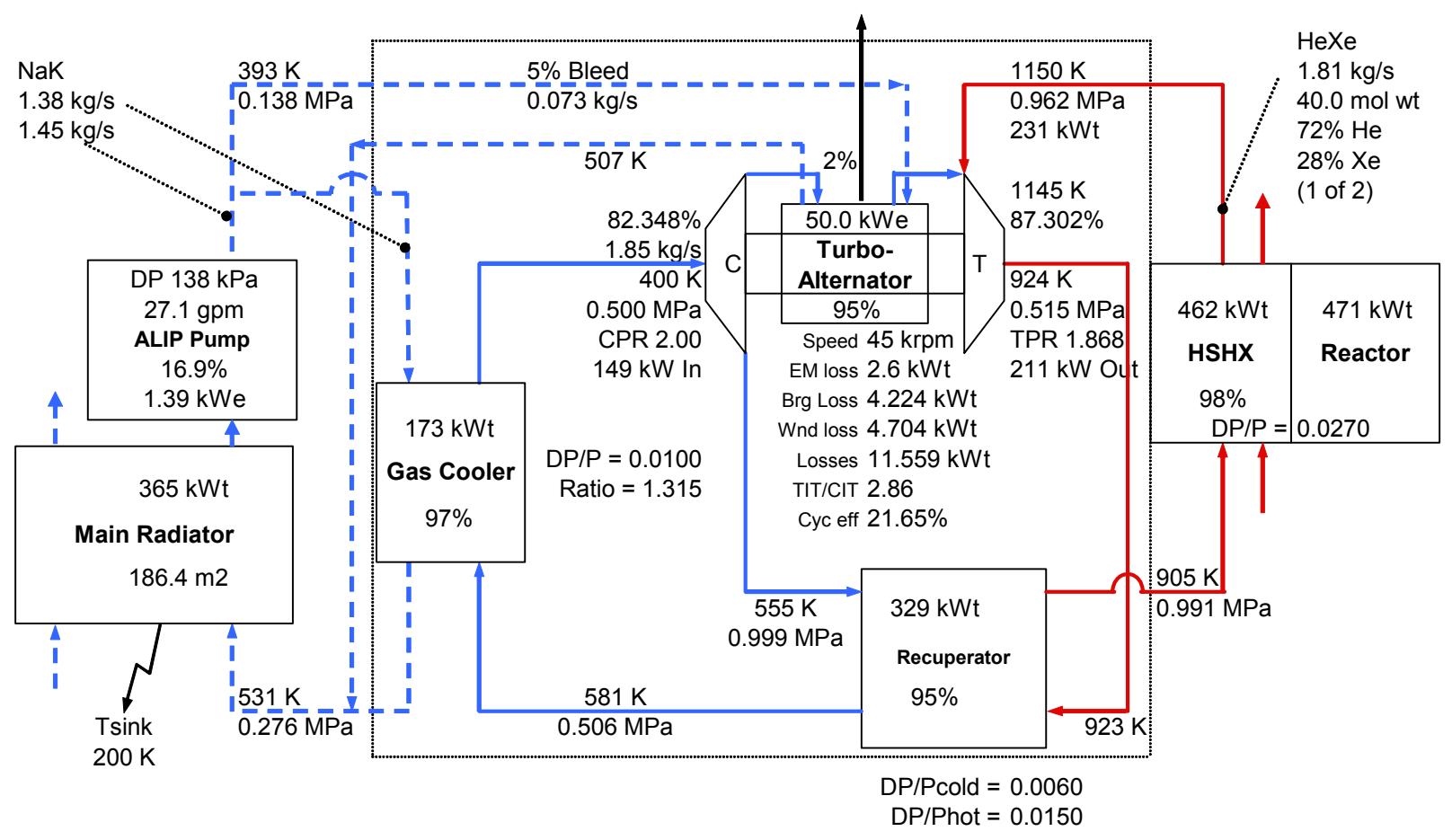

Figure 7. CBC with map-based turbomachinery $\eta, 2 \%$ compressor bleed, bearing, windage, and EM losses.

$32 \%$. As the converter efficiency falls, more heat input is required, more heat rejection is required, cycle state points vary, auxiliary loads change accordingly, and system mass estimates increase. Blending empirical and geometric mass estimators (discussed in section VI.), the combined CBC and HRS subsystem mass estimates increases from $1899 \mathrm{~kg}$ to $2308 \mathrm{~kg}$ - a jump of nearly $22 \%$. This example suggests that if a designer can tolerate $30 \%$ overestimation of efficiency or $22 \%$ underestimation of subsystem mass, the model of Fig. 2 would be adequate. In the conceptual design phase, a $22 \%$ underestimation of mass could deplete an entire subsystem mass margin allocation. Additionally, in even the earliest conceptual design for a space power system, $30 \%$ error in calculated efficiency is unacceptable. Conducting $\mathrm{CBC}$ analyses without consideration of realistic turbomachinery efficiencies, mechanical losses and electromagnetic losses is at best troublesome and at worst seriously misleading. Unfortunately, the fidelity level at which previous "non-CCEP" studies have been conducted is unclear.

Higher-level system models are often used during the integrated conceptual design of a spacecraft. Estimates from high-fidelity subsystem models serve as inputs to the larger space-system-level mass and performance optimization tool. By necessity, parametric representation of the subsystem is frequently used to simplify the higher-level model. Caution must be exercised to ensure the representation in the simplified model is relevant to the question the larger model is being used to address. At a minimum, design points derived from the simplified parametric model must be verified using the high-fidelity code. (As a matter of good design practice, the parameterization and verification steps inherently require a high-fidelity model exist.) As computing power continues to increase, more and more subsystem details can be added to higher-level models, but a fidelity difference between subsystem and space system models will likely remain.

\section{B. Transient}

\section{Analytical Formulation}

Integrated transient models are used to evaluate dynamic subsystem interactions such as nuclear reactor and power conversion control algorithms. When building transient models, the same fundamental issue arises - what level of fidelity is required? In the gas-turbine controls community, three levels of transient models are often discussed: detailed nonlinear thermodynamic models, linearized dynamic models, and real-time piecewise linear dynamic models (RPLDM) ${ }^{17}$. The aforementioned CCEP results are examples of detailed thermodynamic nonlinear model output. Due to the computational complexity of detailed nonlinear models, they are most often used in 
engine and subsystem design capacity without real-time implementation. Linearized models are created using the detailed nonlinear model for performance characterization around an operating point. By selecting a number of discrete operating points, linearized model coefficients can be combined with nonlinear steady-state operating curves to create an RPLDM for system control schemes. (A complication to note regarding RPLDM implementation in a control algorithm is that characteristics of each "as built" engine will differ. Flexibility in early model architecture must be maintained to allow customization for each engine controller.)

As it is for any model, the predicted subsystem performance from a dynamic model is only as good as the fidelity captured in the code. In addition to the aforementioned steady-state fidelity issues associated with performance and loss modeling, in a transient model, the desired fidelity is often a question of what timescales are present in the problem. Fortunately, in the development of $\mathrm{CBC}$ subsystems for space applications, at least three distinct timescales present themselves and can often be used to clarify modeling needs. The characteristic electrical, mechanical and thermal timescales in a CBC PCS design problem may differ by orders of magnitude.

For instance, as user loads are shorted or switched on and off, the electrical voltage and current transients typically represent millisecond or smaller-order timescales. An alternator's managed response to an ion thruster recycle event ${ }^{18}$ recorded in Fig. 8 serves as a good example of this type of timescale response. As the thruster shorts and resets (a recycle), the parasitic load in the system is adjusted such that the alternator voltage and current transients last less than 6 milliseconds.

Displaying a slightly slower response, dependent upon component geometries and rotational speeds, shaft dynamics may be represented by millisecondto-second characteristic times. For instance, a graph showing shaft speed of a $2-\mathrm{kWe}$ CBC during transient testing of commanded shutdown and restart ${ }^{19}$ is shown in Fig. 9 .

Slower yet (although there are exceptions), subsystem level thermal timescales tend to be the longest - ranging from seconds to hours. A Brayton solar-dynamic system thermal response to heat flux variation during a ground test simulating orbital operations $^{3}$ is captured in Fig. 10. If through examination of the governing differential equations, an engineer can estimate and isolate the timescales in the problems of interest, simplifications in transient modeling may be achieved by separating the inconsequential physical phenomenon from the relevant factors and removing the unimportant parameters from the models.

For example, when trying to estimate the power profile and total energy required to start a $\mathrm{CBC}$ converter from rest, the electrical and mechanical timescales dominate the initial system response. A multi-kilowatt $\mathrm{CBC}$ turboalternator using gas-film, compliant-foil bearings is easily capable of

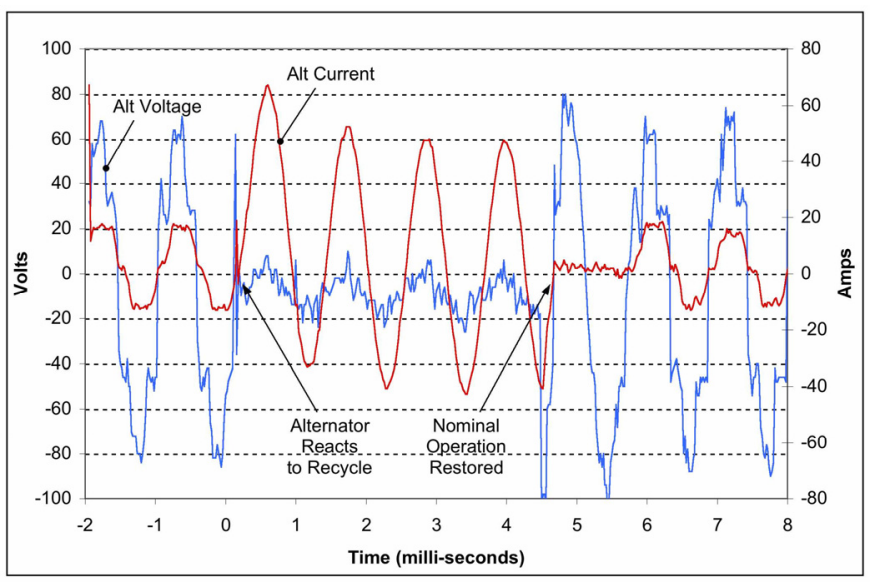

Figure 8. Alternator transient during a thruster recycle.

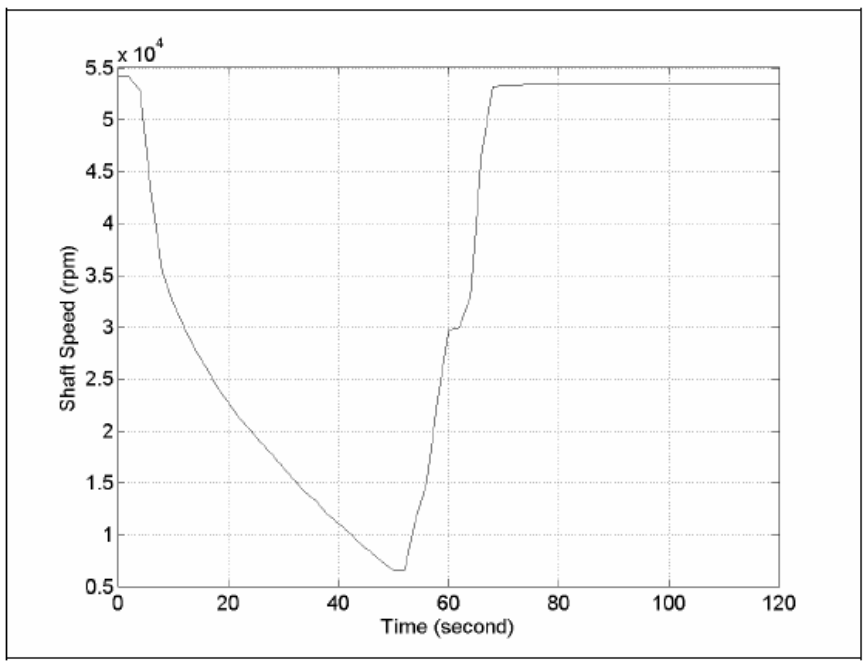

Figure 9. Shaft speed during transient testing.

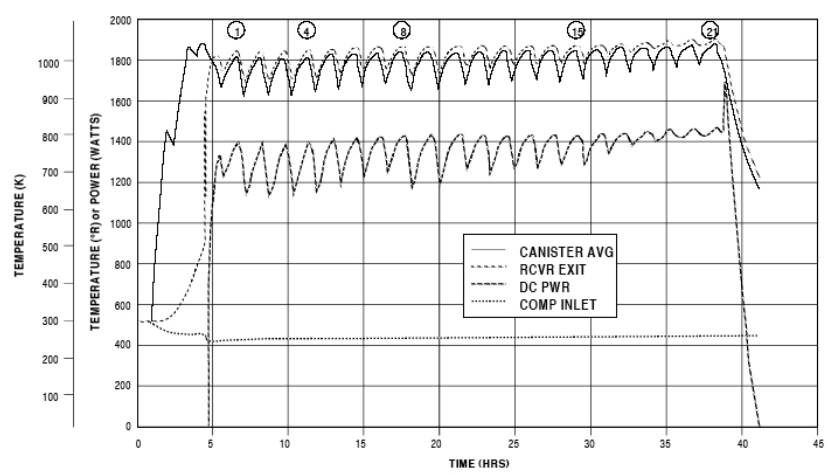

Figure 10. Thermal variation of solar-dynamic Brayton. 
achieving "lift-off" (when the foils lift off of the shaft and the shaft is hydrodynamically supported by the gas film) in less than one second. After lift-off, the system is "motored" (using the alternator as a motor to rotate the shaft) until the system reaches a thermofluid transition point at which the converter becomes self-sustaining and power producing. Depending on the size and performance characteristics of the converter, the thermal response may take minutes. To simplify transient modeling efforts addressing start-up power profiles, a short-time-scale electromechanical model of the turboalternator (including the shaft and bearings but ignoring the thermal response of the $\mathrm{CBC}$ system) might be adequate to predict the initial power profile in the first second. The short-time model would simulate parameters such as motor torque, break-away torque, shaft inertia and bearing contact friction. A second model considering the subsystem thermal response and motoring time needed until self-sustaining action is reached would address component mechanical losses and thermal capacitances to allow integration at larger time scales thereby completing the power profile and energy estimates. The simplification achieved by timescale identification and separation often leads to easier model development and execution. Yet, one must still be sensitive to possible exceptions. For instance, if the relatively fast thermal response of the bearing foils is relevant to the contact friction phenomenon, a locally integrated thermal model may still be needed in the start-up analysis.

\section{Experimental Validation}

As characteristic scales are being evaluated, it is worthwhile to consider what methods will be used to verify model predictions. To attain reasonable confidence in predictive capabilities, models (steady-state and transient) must be validated using empirical data. When planning an experiment to validate a highly integrated dynamic model, similitude of critical dimensionless scales is desirable. The degree to which dimensionless scales are not matched directly impacts the credibility of the verification. For example, a simple lumped-capacitance thermal model of an isolated, insulated duct in a Brayton system is characterized by the first-order ordinary differential equation representing conservation of energy,

$$
\rho V c \frac{d T}{d t}+h_{c} A\left(T-T_{e}\right)=0
$$

The familiar temperature time-response equation results,

$$
\Theta(t)=e^{-t / \tau}
$$

The characteristic time constant, $\tau$, is made up of physically significant duct and flow parameters,

$$
\tau=\rho V c / h_{c} A
$$

To increase the usefulness of a validation experiment, the experimental apparatus used to generate integrated duct model verification data should possess a similar time constant to a flight-like system. A 10 -cm diameter castiron commercial pipe flowing air with a time constant of $184 \mathrm{~s}$ may not be a good representation of a stainless steel flight-like compressor inlet duct flowing He-Xe with a time constant of $62 \mathrm{~s}$. Certainly, this is an over-simplified example - an experiment is not needed to provide the first-order solution. However, for components with complicated geometries and multiple characteristic scales (such as a heat exchanger), the opportunity to achieve similitude is quickly lost as non-prototypic hardware enters a verification test loop. Even if something as simple as the lumped-capacitance time scale is matched, it may be of very limited use. Biot numbers, $B i=h_{c} D / k_{s}$, for the aforementioned duct cases are significantly greater than 0.1 ; this invalidates the lumped-capacitance assumption altogether. Even as higher-order models are developed, integrated experiments using flight-like components are required to verify that modeling assumptions still do not oversimplify the problem.

\section{Cycle Sensitivity}

Thermodynamic performance of $\mathrm{CBC}$ energy converters can be strongly affected by individual component characteristics. Even in the oversimplified Fig. 1 representation, the overall converter efficiency is very sensitive to recuperator effectiveness. Turbomachinery efficiencies and heat exchanger effectivenesses are commonly known to influence cycle performance. However, cycle sensitivity to parameters such as bearing film thickness or alternator gap size is less recognized. 
Bearing film thickness and alternator gap size both affect the total frictional losses associated with shaft rotation. These viscous losses directly rob the turbine of useful shaft work. For a converter that runs at $25 \%$ efficiency, each kilowatt of viscous loss can require up to one kilowatt of heat rejection and $4 \mathrm{kWt}$ in additional heat source supply capability (a fraction of the viscous heating can be recovered as useful work if the heated fluid travels through the recuperator or turbine). The selection of an appropriate design-point bearing film thickness is an extremely complicated trade study involving items such as bearing load capacity, bearing and shaft geometry, off-design expectations, thermal management and rotordynamics. Likewise, trades in electromagnetic efficiency, rotordynamics, material properties, and operating stresses are needed to set the operating "air" gap distance in the

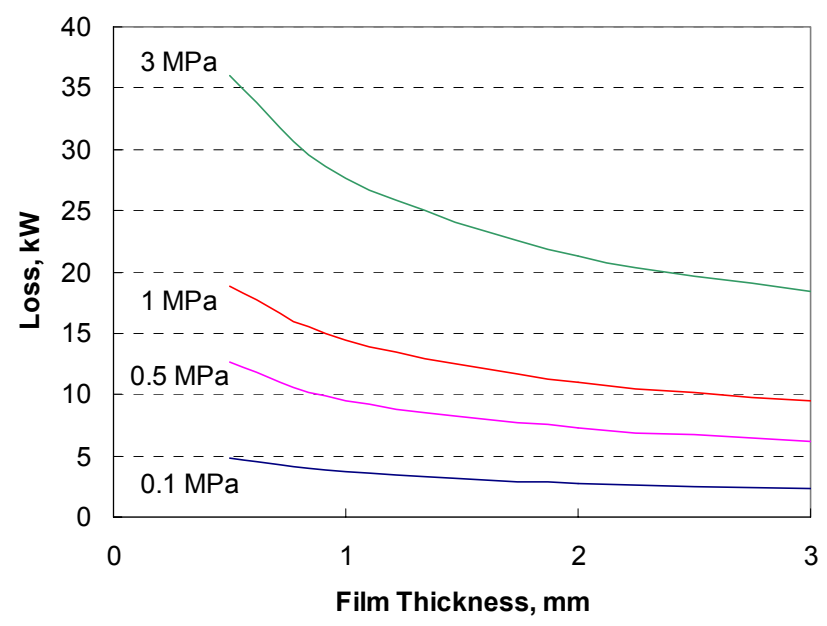

Figure 11. Windage loss estimator. alternator. Since the cycle working fluid is sheared in the bearing-film and alternator-gap separations, mechanical losses (bearing and windage) are significantly impacted by the separation values. Figure 11 presents a gross windage loss estimator as film thickness and peak operating pressure vary for a $100 \mathrm{kWe}$ system. (For thrust and journal bearings, effective film thickness and operating pressure cannot be treated as independent parameters; bearing load capacity couples the two parameters and requires load estimates to optimize the thickness setting.) In the windage model results of Fig. 11, loss estimates become significant at the higher pressures. These losses cause cycle optimized state points to change. The more intricate loss models encompassed in CCEP $^{16}$ allow us to evaluate cycle sensitivities to loss estimates. Comparing Figs. 5-7 and 12 identifies cycle impacts due to mechanical loss sensitivities. At a peak operating pressure of $1 \mathrm{MPa}$, Fig. 7 shows total mechanical losses of approximately $9 \mathrm{~kW}$; at $3 \mathrm{MPa}$, Fig. 12 totals $23 \mathrm{~kW}$ of mechanical losses. Unfortunately, significant variation exists in different loss models. Figure 13 shows a cycle similar to that of Fig. 12 but using a different empirical loss model. ${ }^{9}$ The mechanical losses shown in Fig. 13 at $3 \mathrm{MPa}$ are less than $14 \mathrm{~kW}$ (a $40 \%$ reduction); a related increase in Fig. 12 to

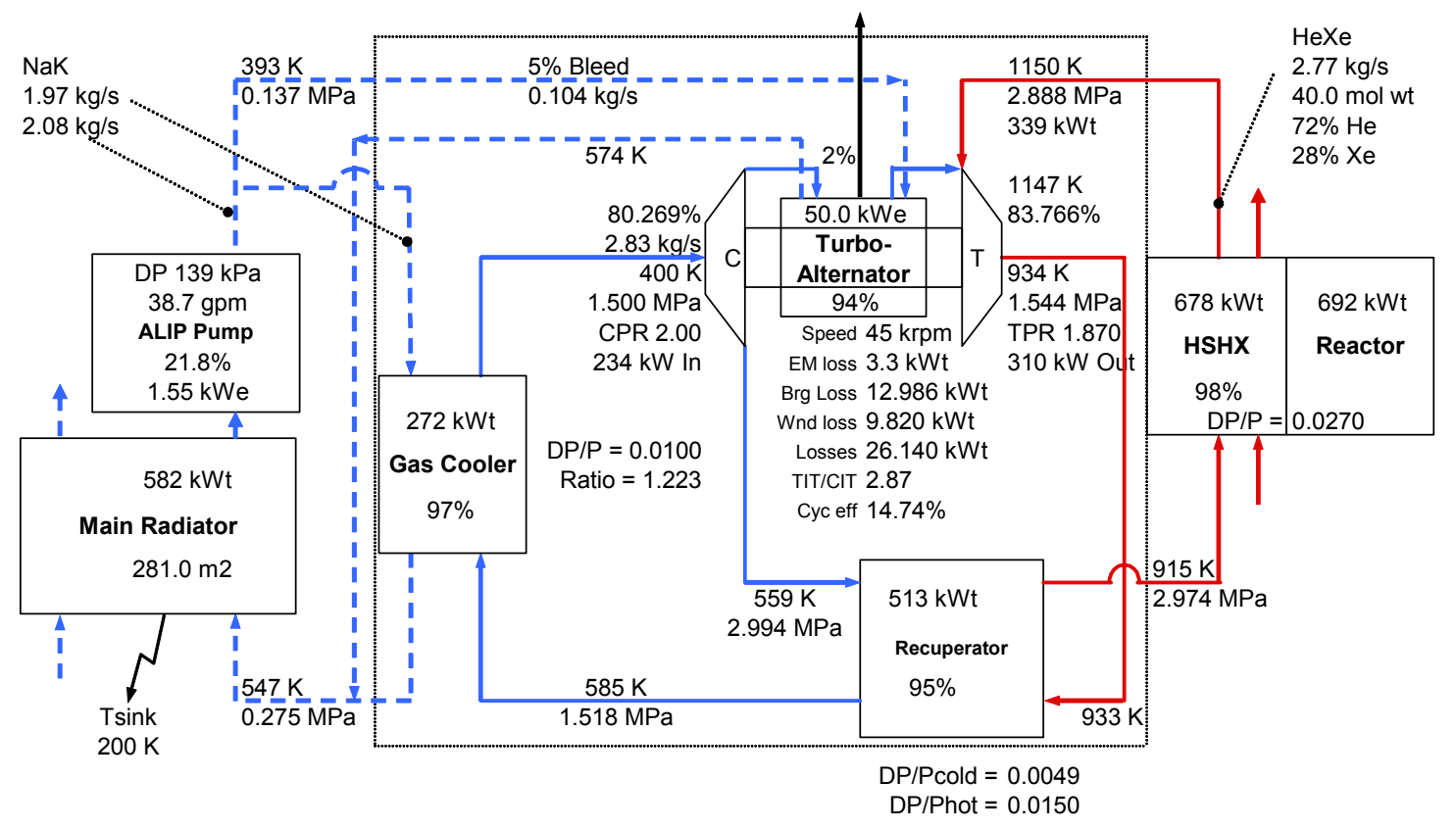

Figure 12. CBC at 3MPa peak cycle pressure; includes map-based turbomachinery $\eta, 2 \%$ compressor bleed, bearing, windage, and EM losses. 


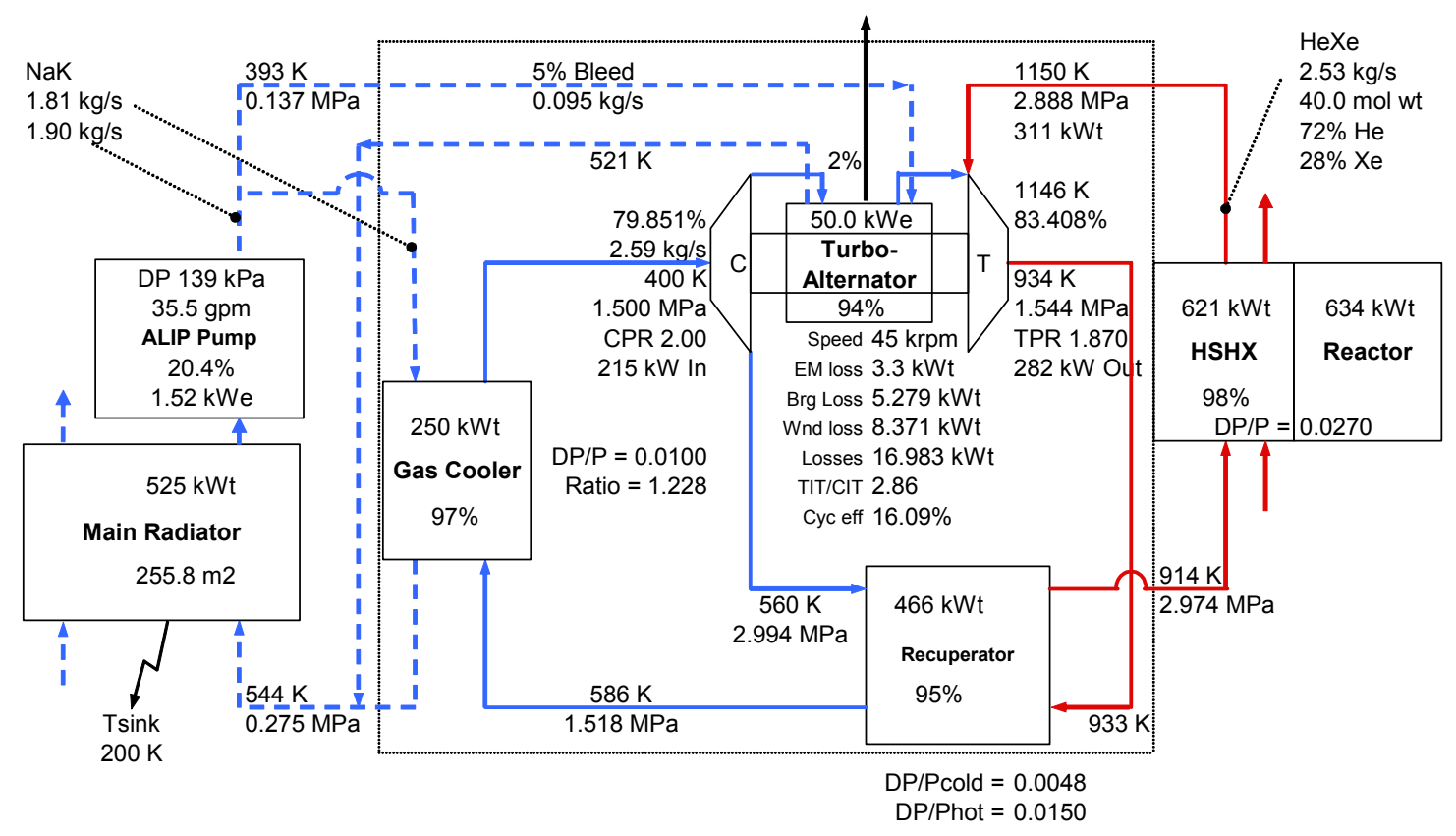

Figure 13. CBC at 3MPa peak cycle pressure; includes map-based turbomachinery $\eta, 2 \%$ compressor bleed, and alternate loss model.

Fig. 13 converter efficiency from $14.7 \%$ to $16.1 \%$ is noted. Not only is converter efficiency affected, but other design factors are also sensitive to mechanical losses. For example, start-up auxiliary power requirements are heavily influenced by mechanical loss and total motoring time estimates. To reduce the uncertainty associated with loss estimates, a focused research program is currently underway at the NASA Glenn Research Center. The research will better quantify bearing and windage mechanical losses under different operating conditions in fluids of various molecular weights and correlate the observed losses with a physics-based loss model.

\section{Mass Models}

In $\mathrm{CBC}$ conceptual design models, two methods of mass estimation are prevalent. The first method uses empirical curve fits that present "as-built" component masses as a function of a few (frequently one) characteristic performance variables. The second method is to have a detailed geometric characterization of the component and determine the mass by summing the known volume and material density products. Both methods have advantages and disadvantages.

The empirical method is generally simpler and easily included in higher-level integrated system models. For example, to size a turboalternator or $\mathrm{CBC}$ heat exchanger, the specific mass $(\mathrm{kg} / \mathrm{kW})$ curves in Figs. 14 and 15 could be used. The curves are anchored by prototypical hardware built as part of previous research programs. (Uncertainties due to few "as-built" data points can, of course, propagate to large uncertainties in subsystem mass estimates.) If the empirical method is used, unjustified extrapolation outside the empirical database must be avoided. Additionally, without a more detailed physical model to scale the hardware, the modeler relies on the completeness of the independent variables identified. Because of the problems listed, it is often difficult to fully assess the impact of advanced technologies using historical hardware-based functional relationships.

The use of more detailed component design information provides a second mass estimation method. Using this technique, the CCEP code manipulates information such as that given in Table 1 to estimate the mass of a plate-fin counterflow recuperator. The detailed information seems to yield a more fundamental mass calculation, but one must recognize that other empirical relationships (such as pressure-drop and heat transfer correlations) are involved in producing the detailed geometric configuration. If the design details are generated using a fundamental physicsbased algorithm, this method can usually be successfully adapted to investigate advanced technologies (like new materials, fabrication methods, etc.). This method is also less constrained by designs that lie outside the historical database. However, whenever a conceptual design estimate can be validated with "as-built" reference data in a reasonable and unrestrained manner, the hardware-based comparison is usually preferred. 


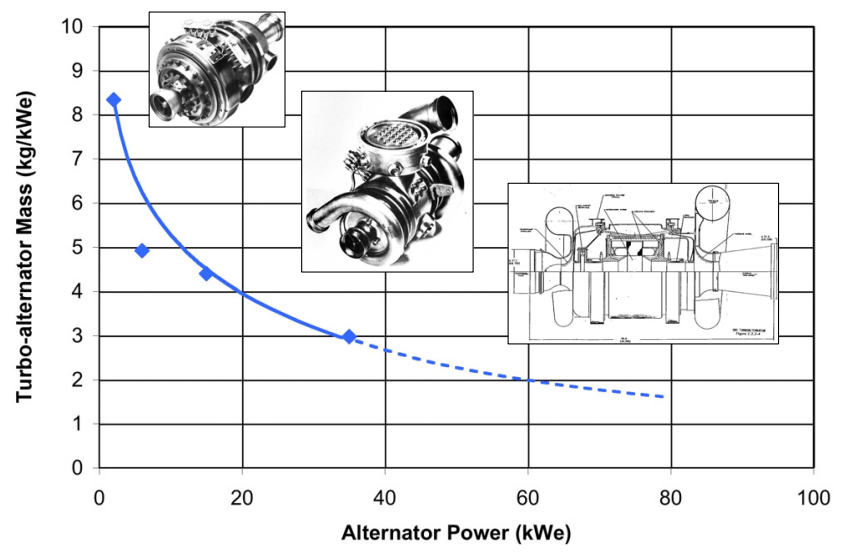

Figure 14. Specific mass curve for turboalternators.

\section{Conclusions}

Each performance model's required capabilities are driven by the design question being investigated. However, as a general recommendation, to attain acceptable results, conceptual design analyses used to size closed-Brayton-cycle space power conversion subsystems must include realistic representations of turbomachinery efficiencies, mechanical losses and electromechanical losses. Efficiency errors of $30 \%$ and mass estimate errors of $20 \%$ are possible using even moderately unrealistic representations.

Transient CBC performance models can benefit from timescale identification and segregation. Characteristic electrical, mechanical and thermal timescales in closedBrayton-cycle subsystems can vary from fractions of milliseconds to hours. Simpler development and use of integrated dynamic models may be possible using timescale separation techniques.

Dimensionless similitude between ground test units and flight systems is essential to meaningful experimental validation of transient models. Special attention must be devoted to evaluating ground test hardware with respect to flight-like characteristic dimensionless scales.

Cycle energy balances are sensitive to mechanical losses in bearings and alternators. Comprehensive bearing and windage loss models are difficult to generate due to the complexity and number of variables in the related trade spaces. Existing loss models yield significantly different loss predictions. Using two available models, a $40 \%$ difference in mechanical loss predictions was demonstrated for a $100-\mathrm{kWe}$ (two-engine) closed-Braytoncycle subsystem operating at $3 \mathrm{MPa}$ peak pressure. More research is needed to reduce the uncertainty in journal and thrust bearing loss predictions over a range of operating conditions using fluids of various molecular weights.

Closed-Brayton-cycle subsystem mass estimates are typically empirically based or calculated from more detailed component design information. Both methods

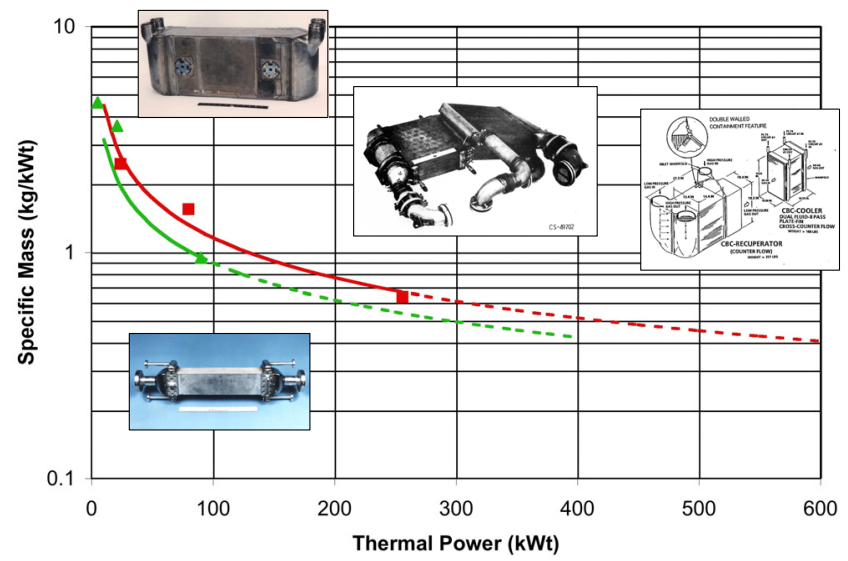

Figure 15. Specific mass curves for heat exchangers.

Table 1. Recuperator geometric characterization.

Recuperator

\begin{tabular}{|c|c|}
\hline$\underline{\text { Item }} \quad \underline{\text { Value }}$ & $\underline{\text { Units }}$ \\
\hline 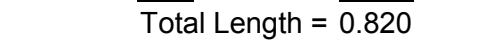 & $\mathrm{m}$ \\
\hline Total Width $=0.325$ & $\mathrm{~m}$ \\
\hline Total Height $=0.459$ & $\mathrm{~m}$ \\
\hline Divider Plate Thick $=0.000203$ & $\mathrm{~m}$ \\
\hline Sideplate Thick $=0.00254$ & $\mathrm{~m}$ \\
\hline $\begin{array}{l}\text { Outer shell Thick }=0.00356 \\
\text { Headers }\end{array}$ & $\mathrm{m}$ \\
\hline Item Value & Units \\
\hline Inlet Header Length $=\overline{0.193}$ & $\mathrm{~m}$ \\
\hline Inlet Header Width $=0.248$ & $\mathrm{~m}$ \\
\hline Outlet Header Length $=0.203$ & $\mathrm{~m}$ \\
\hline Outlet Header Width $=0.257$ & $\mathrm{~m}$ \\
\hline Fin Pitch $=197$ & fins $/ m$ \\
\hline Fin Length $=\mathrm{N} / \mathrm{A}$ & \\
\hline Fin Thickness $=0.0001524$ & $\mathrm{~m}$ \\
\hline Core General & \\
\hline Item Value & Units \\
\hline 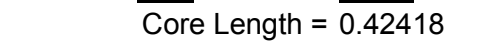 & $\mathrm{m}$ \\
\hline Core Width $=0.313182$ & $\mathrm{~m}$ \\
\hline Fin Pitch $=630$ & fins $/ \mathrm{m}$ \\
\hline Fin Length $=0.00318$ & $\mathrm{~m}$ \\
\hline Fin Thickness $=0.0001524$ & $\mathrm{~m}$ \\
\hline Cold Stream Core (High Pressure) & \\
\hline Item Value & Units \\
\hline 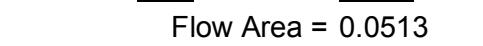 & $\mathrm{m} 2$ \\
\hline Plate Spacing $=0.00318$ & $\mathrm{~m}$ \\
\hline$D_{H Y D}=0.001946$ & $\mathrm{~m}$ \\
\hline \# Sandwiches $=60$ & \\
\hline Heat Xfer Area $=46.5$ & $\mathrm{~m} 2$ \\
\hline Hot Stream Core (Low Pressure) & \\
\hline Item $\quad$ Value & $\underline{\text { Units }}$ \\
\hline 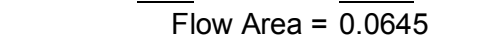 & $\mathrm{m} 2$ \\
\hline Plate Spacing $=0.00389$ & $\mathrm{~m}$ \\
\hline $\mathrm{D}_{\mathrm{HYD}}=0.002073$ & $\mathrm{~m}$ \\
\hline \# Sandwiches $=61$ & \\
\hline Heat Xfer Area $=54.9$ & $\mathrm{~m} 2$ \\
\hline
\end{tabular}

Recuperator mass $=158 \mathrm{~kg}$ 
have advantages and disadvantages but, if not overly constraining, grounding a mass estimate in "as-built" data is frequently advantageous.

\section{References}

${ }^{1}$ Baggenstoss W.G., and Ashe, T.L., "Mission Design Drivers for Closed Brayton Cycle Space Power Conversion Configuration," ASME Journal of Engineering for Gas Turbines and Power, Vol. 114, No. 4, 1992, pp. 721-726.

${ }^{2}$ Harty, R.B., Otting, W.D., and Kudija, C.T., “Applications of Brayton Cycle Technology to Space Power,” Proceedings of Intersociety Energy Conversion Engineering Conference (IECEC 1993), ACS Publications, Washington, DC, 1993, pp. 463-467.

${ }^{3}$ Shaltens R.K., and Mason, L.S., "Early Results from Solar Dynamic Space Power System Testing," AIAA Journal of Propulsion and Power, 1996, pp. 852-858.

${ }^{4}$ Hyder, A.K., Wiley, R.L., Halpert, G., Flood, D.J., and Sabripour, S., Spacecraft Power Technologies, Imperial College Press, London, 2000, pp. 332-340.

${ }^{5}$ Mason, L.S., "A Power Conversion Concept for the Jupiter Icy Moons Orbiter," AIAA Journal of Propulsion and Power, Vol. 20, No. 5, 2004, pp. 902-910.

${ }^{6}$ Tilliette, Z.P., "Adaptability of Brayton Cycle Conversion Systems to Fast, Epithermal and Thermal Spectrum Space Nuclear Reactors," Proceedings of Intersociety Energy Conversion Engineering Conference (IECEC 1988), ASME Publications, New York, 1988, pp. 197-202.

${ }^{7}$ Owen, D.F., "SP-100/Brayton Power System Concepts," Proceedings of Intersociety Energy Conversion Engineering Conference (IECEC 1989), IEEE Publications, Los Alamitos, CA, 1989, pp. 1257-1262.

${ }^{8}$ Barrett, M.J., and Reid, B.M., "System Mass Variation and Entropy Generation in 100-kWe Closed-Brayton-Cycle Space Power Systems," Proceedings of Space Technology and Applications International Forum (STAIF-2004), edited by M. El-Genk, AIP Conference Proceedings 699, New York, 2004, pp. 445-452.

${ }^{9}$ Johnson, P.K., and Mason, L.S., "Design and Off-Design Performance of $100 \mathrm{kWe}-$ Class Brayton Power Conversion Systems," Proceedings of Space Technology and Applications International Forum (STAIF-2005), edited by M. El-Genk, AIP Conference Proceedings 746, New York, 2005, pp. 711-718.

${ }^{10}$ Traverso, A., Calzolari, F., and Massardo, A., "Transient Analysis of and Control System for Advanced Cycles Based on Micro Gas Turbine Technology," Proceedings of ASME Turbo Expo 2003, Vol. 3, ASME, New York, 2003, pp. $201-209$.

${ }^{11}$ Traverso, A., "TRANSEO Code for the Dynamic Performance Simulation of Micro Gas Turbine Cycles," Proceedings of ASME Turbo Expo 2005, ASME, New York, 2005, GT2005-68101.

${ }^{12}$ Ulfsnes, R.E., Bolland, O., and Jordal, K., "Modeling and Simulation of Transient Performance of the Semi-closed $\mathrm{O}_{2} / \mathrm{CO}_{2}$ Gas Turbine Cycle for $\mathrm{CO}_{2}$-capture," Proceedings of ASME Turbo Expo 2003, Vol. 3, ASME, New York, 2003, pp. 65-74.

${ }^{13}$ Wright, S.A., "Preliminary Results of a Dynamic System Model for a Closed-loop Brayton Cycle Coupled to a Nuclear Reactor," Proceedings of $1^{\text {st }}$ International Energy Conversion Engineering Conference (IECEC 2003), AIAA, Washington, DC, 2003.

${ }^{14}$ Fishbach, L.H., and Caddy, M.J., "NNEP - The Navy/NASA Engine Program," NASA TM X-71857, NASA Lewis Research Center, Cleveland, OH, 1975

${ }^{15}$ Klann, J.L., and Staiger, P.J., "Design Tradeoffs for a Space Station Solar-Brayton Power System," Proceedings of Intersociety Energy Conversion Engineering Conference (IECEC 1985), Vol. 1, SAE Publications, Warrendale, PA, 1985, pp. 84-97.

${ }^{16}$ Klann, J.L., Closed Cycle Engine Program Operational Manual, NASA Lewis Research Center, Cleveland, Ohio, 1991.

${ }^{17}$ Kulikov, G.G., and Thompson, H.A. (eds.), Dynamic Modeling of Gas Turbines: Identification, Simulation, Condition Monitoring and Optimal Control, Advances in Industrial Control Series, Springer, New York, 2004, pp. 21-25.

${ }^{18}$ Hervol, D., Mason, L., Birchenough, A., and Pinero, L., "Experimental Investigations From the Operation of a $2 \mathrm{~kW}$ Brayton Power Conversion Unit and a Xenon Ion Thruster," NASA TM-2004-212960, NASA Glenn Research Center, Cleveland, OH, 2004.

${ }^{19}$ Le, D.K., and McNelis, A.M., "Validation of a Mechanical Dynamics Model for Closed-Cycle Brayton Engines on a 2kWe Unit,” Report No. SSDB-JIMO-2005-003, NASA Glenn Research Center, Cleveland, OH, October 2004. 


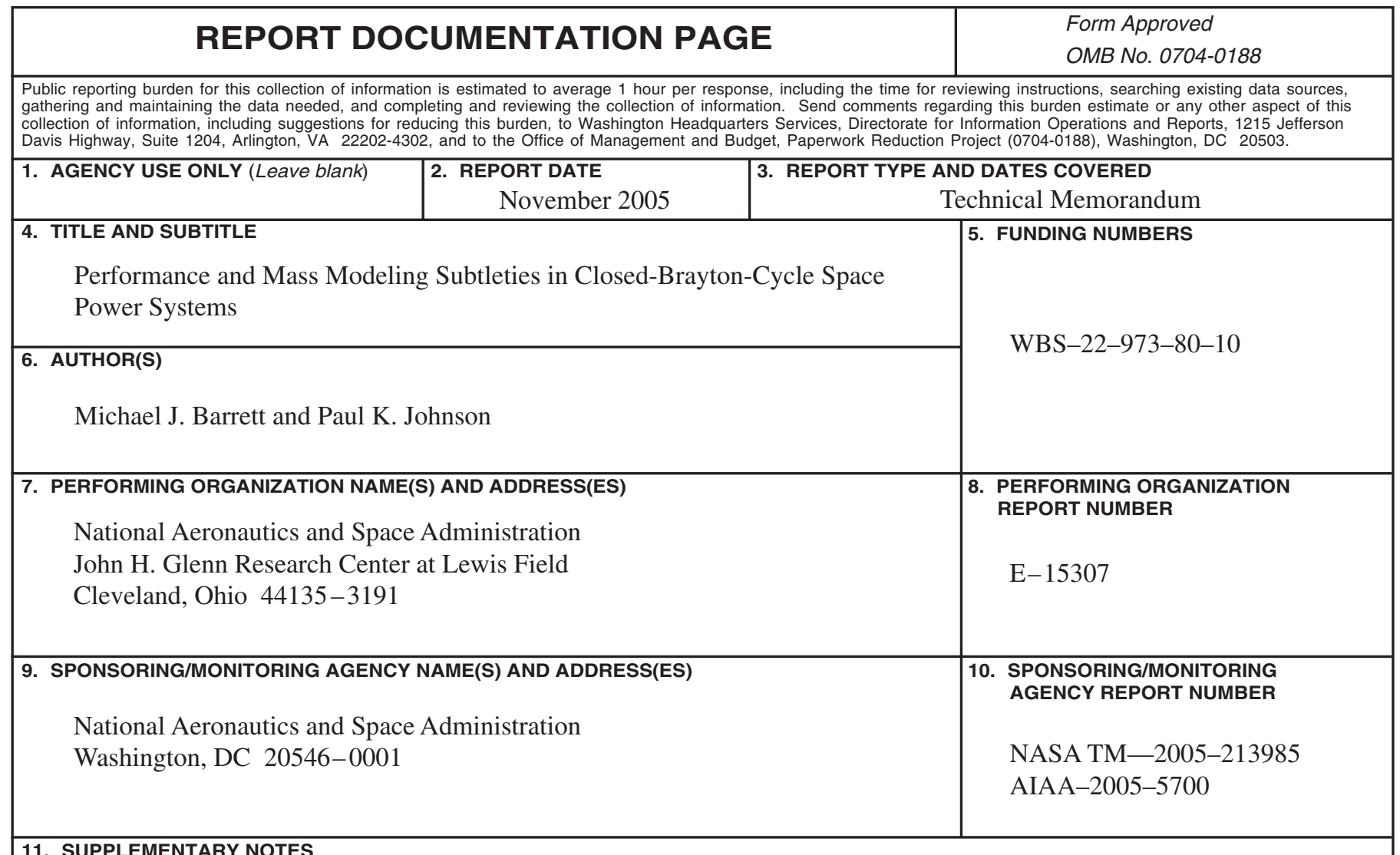

11. SUPPLEMENTARY NOTES

Prepared for the Third International Energy Conversion Engineering Conference sponsored by the American Institute of Aeronautics and Astronautics, San Francisco, California, August 15-18, 2005. Michael J. Barrett, NASA Glenn Research Center; and Paul K. Johnson, Analex Corporation, 1100 Apollo Drive, Brook Park, Ohio 44142. Responsible person, Michael J. Barrett, organization code RPT, 216-433-5424.

12a. DISTRIBUTION/AVAILABILITY STATEMENT 12b. DISTRIBUTION CODE

Unclassified - Unlimited

Subject Category: 20

Available electronically at http://gltrs.grc.nasa.gov

This publication is available from the NASA Center for AeroSpace Information, 301-621-0390.

13. ABSTRACT (Maximum 200 words)

A number of potential NASA missions could benefit from closed-Brayton-cycle (CBC) power conversion systems. The human and robotic mission power applications include spacecraft, surface base, and rover scenarios. Modeling of CBC subsystems allows system engineers, mission planners and project managers to make informed decisions regarding power conversion system characteristics and capabilities. To promote thorough modeling efforts, a critical review of CBC modeling techniques is presented. Analysis of critical modeling elements, component influences and cycle sensitivities is conducted. The analysis leads to quantitative results addressing projections on converter efficiency and overall power conversion system mass. Even moderate modeling errors are shown to easily over-predict converter efficiencies by 30 percent and underestimate mass estimates by 20 percent. Both static and dynamic modeling regimes are evaluated. Key considerations in determining model fidelity requirements are discussed. Conclusions and recommendations are presented that directly address ongoing modeling efforts in solar and nuclear space power systems.

14. SUBJECT TERMS

Closed cycles; Nuclear electric power generation; Turbogenerators 15. NUMBER OF PAGES 18

\begin{tabular}{|c|c|c|}
\hline $\begin{array}{c}\text { 17. SECURITY CLASSIFICATION } \\
\text { OF REPORT } \\
\text { Unclassified }\end{array}$ & $\begin{array}{c}\text { 18. SECURITY CLASSIFICATION } \\
\text { OF THIS PAGE } \\
\text { Unclassified }\end{array}$ & $\begin{array}{c}\text { 19. SECURITY CLASSIFICATION } \\
\text { OF ABSTRACT } \\
\text { Unclassified }\end{array}$ \\
\hline
\end{tabular}



